\title{
CONTRIBUIÇÕES DA EDUCAÇÃO GEOGRÁFICA SIGNIFICATIVA NA PREVENÇÃO DE RISCOS NATURAIS
}

\author{
Contributions of significant geographical education in prevention of natural risks
}
Contribuciones de la educación geográfica significativa en la prevención de riesgos naturales

\begin{abstract}
Camila Bento Bragança* Anice Esteves Afonso**

*Universidade do Estado do Rio de Janeiro / Faculdade de Formação de Professores-FFP camila.b.03@gmail.com

** Universidade do Estado do Rio de Janeiro / Faculdade de Formação de Professores-FFP aniceafonso@gmail.com
\end{abstract}

Recebido em 18/20/2019. Aceito para publicação em 20/10/2019.

Versão online publicada em 10/11/0000 (http://seer.ufrgs.br/paraonde)

\section{Resumo:}

A presença constante de eventos naturais extremos nos últimos anos tanto na Cidade do Rio de Janeiro, da sua Região Metropolitana e Serrana tem contribuído para que essa temática seja mais discutida e abordada tanto nas mídias sociais quanto em projetos escolares de conscientização ambiental. A escola se tornou um meio muito importante e eficiente para difundir e disseminar as informações referentes a riscos naturais, pois é por meio dela que podemos propor uma aprendizagem mais significativa levando em consideração o cotidiano e o espaço de vivência do aluno. Por meio desta aprendizagem significativa, pode-se proporcionar ao aluno a possibilidade dos mesmos em correlacionar os conteúdos ensinados em sala de aula com a sua própria realidade estabelecendo com eficiência os processos de ensino-aprendizagem.Desta forma, tendo como base o projeto elaborado pela DCRJ, elaborou-se um conjunto de palestras em escolas públicas da Cidade de São Gonçalo com estudantes do ensino básico, abordando sobre os principais riscos naturais que ocorrem na Região Metropolitana do Rio de Janeiro (RMRJ) tais como inundações e deslizamentos de terra e conceitos que estão ligados a esses riscos como: risco, vulnerabilidade, instabilidade, desastre, resiliência entre outros. Portanto,este artigo tem como objetivo discutir a importância da discussão da temática de riscos naturais nas escolas públicas como uma forma de aumentar a conscientização dos alunos não só sobre as questões ambientais mais também sobre as situações de risco que os eventos naturais extremos podem causar em populações que vivem em áreas ambientalmente vulneráveis.

Palavras-chave:Riscos Naturais. Educação Significativa.Dinâmica da Natureza.

\begin{abstract}
:
The constant presence of extreme natural events in recent years in the city of Rio de Janeiro, its Metropolitan and Mountainous Region has contributed to this theme being more discussed and addressed in both social media and school projects of environmental awareness. The school has become a very important and efficient way to disseminate and disseminate information regarding natural hazards, because it is through it that we can propose a more meaningful learning considering the student's daily life and living space. Through this meaningful learning, it is possible to provide the student with the possibility to correlate the contents taught in the classroom with their own reality, effectively establishing the teaching-learning processes. Thus, based on the project prepared by the DCRJ, a set of lectures in public schools in the city of São Gonçalo was prepared with elementary students, addressing the main natural risks that occur in the Rio de Janeiro Metropolitan Region
\end{abstract}


(RMRJ). ) such as floods and landslides and concepts that are linked to such risks as: risk, vulnerability, instability, disaster, resilience among others. Therefore, this article aims to discuss the importance of discussing the issue of natural hazards in public schools to increase students' awareness not only about environmental issues but also about the risk situations that extreme natural events can cause in populations living in environmentally vulnerable areas.

Key-words:Natural Hazards. Significant Education. Nature Dynamics

\begin{abstract}
Resumen:
La presencia constante de eventos naturales extremos en los últimos años en la ciudad de Río de Janeiro, su Región Metropolitana y Montañosa, ha contribuido a que este tema sea más discutido y abordado en las redes sociales y proyectos escolares de conciencia ambiental. La escuela se ha convertido en una forma muy importante y eficiente de difundir información sobre los peligros naturales, porque es a través de ella que podemos proponer un aprendizaje más significativo teniendo en cuenta la vida diaria y el espacio vital del estudiante. A través de este aprendizaje significativo, es posible proporcionar al alumno la posibilidad de correlacionar los contenidos enseñados en el aula con su propia realidad, estableciendo efectivamente los procesos de enseñanza-aprendizaje. Por lo tanto, con base en el proyecto preparado por el DCRJ, se preparó una serie de conferencias en escuelas públicas de la ciudad de São Gonçalo con estudiantes de primaria, abordando los principales riesgos naturales que ocurren en la Región Metropolitana de Río de Janeiro (RMRJ). ) tales como inundaciones y deslizamientos de tierra y conceptos relacionados con riesgos como: riesgo, vulnerabilidad, inestabilidad, desastres, resiliencia, entre otros. Por lo tanto, este artículo tiene como objetivo discutir la importancia de discutir el tema de los peligros naturales en las escuelas públicas como una forma de aumentar la conciencia de los estudiantes no solo sobre los problemas ambientales sino también sobre las situaciones de riesgo que los eventos naturales extremos pueden causar en poblaciones que viven en zonas ambientalmente vulnerables.
\end{abstract}

Palabras-clave:Peligros naturales. Educación significativa Dinámica de la naturaleza.

\title{
1 Introdução
}

A presença constante de eventos naturais extremos nos últimos anos tanto na Cidade do Rio de Janeiro, da sua Região Metropolitana e Serrana tem contribuído para que essa temática seja mais discutida e abordada tanto nas mídias sociais quanto em projetos e pesquisas voltadas tanto para a educação ambiental quanto para projetos de mitigação e prevenção de riscos naturais. Entretanto, muitas propostas foram articuladas e apresentadas ao público como a campanha "Construindo Cidades Resilientes" que foi lançada em 2010 durante o período que correspondeu ao marco de ação de Hyogo (2005-2015) que propôs medidas para se alcançar a resiliência local minimizando os desastres tendo como uma das bases a Educação Ambiental e o Marco de Sendai (20152030) que também veio para complementar esta iniciativa no intuito de fortalecer e reforçar a importância da adoção de medidas e/ou estratégias para aumentar o poder de resiliência das populações que convivem com o risco além das ações governamentais de políticas públicas eficientes que pudessem contribuir para minimizar os efeitos dos desastres naturais.

A escola se tornou um meio muito importante e eficiente para difundir e disseminar as informações referentes a riscos naturais, pois é por meio dela que podemos propor uma aprendizagem mais significativa levando em consideração o cotidiano e o espaço de vivência do aluno. Por meio desta aprendizagem significativa, pode-se proporcionar ao

ParaOnde!?, Porto Alegre, v.12 n.2, p.89-95, 2019.http://seer.ufrgs.br/paraonde Edição Especial - III Colóquio de Pesquisadores em Geografia Física Ensino de Geografia 
aluno a possibilidade dos mesmos em correlacionar os conteúdos ensinados em sala de aula com a sua própria realidade estabelecendo com eficiência os processos de ensinoaprendizagem.

O ensino de Geografia Física em sala de aula proporciona ao aluno a compreensão dos fatores físico-ambientais que fazem parte da dinâmica da natureza e a identificar as possíveis situações de riscos naturais que podem ocorrer no seu espaço de vivência. Isto Ihes proporcionam a desenvolver a sua percepção de risco e através disso a terem um olhar diferenciado sobre os espaços em que se deslocam. A educação geográfica dentro deste contexto se torna importante, pois a Geografia á a ciência que estuda o espaço geográfico e as relações que são estabelecidas nele, principalmente as relações que são estabelecidas entre o homem e a natureza, portanto a geografia estimula a pensar 0 mundo de forma crítica e a saber se colocar e se posicionar nele de modo a saber agir no espaço respeitando os limites da natureza.

"A Geografia serve para muitos fins: organizar territórios, definir políticas de ocupação espacial, escolher onde construir estradas ou pontes, cultivar produtos, extrair recursos... Ora, a Geografia serve para muita coisa, e serve, principalmente, para que as pessoas (grupos sociais, comunidades, nações, exércitos, sociedades...) façam escolhas e criem estratégias para agir sobre a realidade espacial". (Afonso, 2013, p.12)

Por isso, a temática de riscos naturais juntamente com a compreensão dos fatores físicos-ambientais contribui para o entendimento da dinâmica da natureza e para compreender as situações de riscos naturais, aproveitar os conhecimentos cotidianos dos alunos pode ser uma estratégia eficiente para estimular a aprendizagem significativa desse conteúdo, pois o homem ao agir sobre o espaço geográfico ele diretamente ou indiretamente interfere nas dinâmicas da natureza modificando-a ou promovendo a sua degradação. Segundo Afonso (2013, p.27) "Onde quer que você esteja, as formas de relevo estarão presentes. Haverá um morro, um rio, a planície, a serra ou a praia. As cidades, os cultivos, as fábricas e estradas estão sobre as formas de relevo, e com elas interagem".

Desta forma,este artigo tem como objetivo discutir a importância da discussão da temática de riscos naturais nas escolas públicas como uma forma de aumentar a conscientização dos alunos não só sobre as questões ambientais mais também sobre as situações de risco que os eventos naturais extremos podem causar em populações que vivem em áreas ambientalmente vulneráveis e sujeitas a dinâmica natural. "Sabe-se que os eventos naturais como os deslizamentos e inundações fazem parte da dinâmica da natureza e são processos constantes na história do nosso planeta" (CEPED/UFSC, 2012).

\section{Desenvolvimento}

Os conteúdos referentes a Geografia Física têm como objetivo entender como o relevo e a sua dinâmica natural interage com os elementos presentes no espaço geográfico. Portanto, o desconhecimento dos processos que envolvem a dinâmica da natureza pode trazer vulnerabilidade para as populações frente aos eventos naturais extremos, por isso o conhecimento e a compreensão das diversas interações que existem no espaço geográfico entre a sociedade e a natureza é de fato importante e deve se tornar prioridade dentro dos conteúdos escolares. Sendo a Geografia a ciência cuja a

ParaOnde!?, Porto Alegre, v.12 n.2, p.89-95, 2019.http://seer.ufrgs.br/paraonde

Edição Especial - III Colóquio de Pesquisadores em Geografia Física Ensino de Geografia 
função é estudar o espaço geográfico, tem como objetivo analisar as interações existentes identificando de que maneira as ações humanas estabelecidas sobre os objetos (relevo, regiões costeiras, áreas de proteção) podem interferir na dinâmica social e natural do ambiente. E isto é essencial para se entender as situações de risco, como os de deslizamentos e inundações que muito ocorrem em algumas paisagens urbanas brasileiras. Desta forma os estudos dos conteúdos da Geografia, principalmente nas aulas referentes a Geografia Física, se tornam uma ferramenta de prevenção de riscos naturais eficaz fortalecendo uma postura mais crítica em relação as ações sociais sobre os espaços urbanos e ao uso e ocupação do solo nas grandes cidades.

A aprendizagem significativa possibilita ao professor o estimulo e técnicas necessárias para promover o processo de ensino- aprendizagem com eficiência. Ela consiste em correlacionar os conteúdos do currículo obrigatório com o cotidiano dos alunos, ou seja, focar naquilo que o aluno sabe, tornando isso como ponto de partida para iniciar os conteúdos escolares. O conteúdo precisa ser significativo para os estudantes a fim de que os mesmos possam manifestar o interesse e a disposição em aprender.

Portanto, a temática de riscos naturais pode ser incluída como um conteúdo relevante e importante a ser ensinado em sala de aula por que fazem ou podem fazer parte de experiencias vividas pelos alunos (além da escola) e isto estimula-os a fazerem parte não só do conteúdo a ser passado, mas também da dinâmica da sala de aula construindo o conhecimento junto com o professor. Entretanto, esta metodologia consiste em um desafio para os profissionais da educação, pois o professor se tornará um mediador entre os estudantes e o conhecimento, ou seja, o aluno e o seu cotidiano de vida se tornam elementos importantes na construção de conhecimentos em sala de aula. $O$ desafio consiste em fazer com que todos em sala de aula possam participar e interagir a fim de alcançar o objetivo de adquirir a aprendizagem eficiente.

O professor precisará provocar a sede em aprender e instigar os estudantes a problematizar o tema e a propor soluções e a temática de riscos naturais poderá proporcionar esta possibilidade, pois ao aprender e compreender as dinâmicas naturais do ambiente em que vivemos, poderá a partir daí a propor soluções de prevenção e portanto tornando-se resiliente, ou seja, sabe lidar da melhor maneira possível com a possibilidade de ocorrência de um evento natural extremo, diminuindo assim a sua vulnerabilidade.

Com a metodologia da aprendizagem significativa e através da parceria do grupo de pesquisa "Ensino de Geografia Física e Formação de Professores" do DGEO/FFP/UERJcom a Defesa Civil da Cidade do Rio de Janeiro (DCRJ) por meio do projeto criado pela Subdec- Subsecretaria de Defesa Civil- titulado como "Defesa Civil nas Escolas" com a atividade lúdica de fixação dos conteúdos trabalhados o "Mapeamento de Riscos". Elaborou-se um conjunto de palestras com o intuito de disseminar as informações referentes a riscos naturais nas escolas na tentativa de ampliar e fortalecer a política de prevenção e mitigação de risco em áreas vulneráveis, a fim de minimizar os danos provenientes da dinâmica da natureza aumentando o poder de resiliência das comunidades ao redor das escolas participantes por meio dos estudantes que são vistos pelos profissionais da DC como potenciais disseminadores de informações.

Desta forma, tendo como base o projeto elaborado pela DCRJ, elaborou-se um conjunto de palestras em escolas públicas da Cidade de São Gonçalo com estudantes do ensino básico, abordando sobre os principais riscos naturais que ocorrem na Região

ParaOnde!?, Porto Alegre, v.12 n.2, p.89-95, 2019.http://seer.ufrgs.br/paraonde Edição Especial - III Colóquio de Pesquisadores em Geografia Física Ensino de Geografia 
Metropolitana do Rio de Janeiro (RMRJ) tais como inundações e deslizamentos de terra e conceitos que estão ligados a esses riscos como: risco, vulnerabilidade, instabilidade, desastre, resiliência entre outros. Foi discutido também temas sobre as chuvas fortes e suas consequências em ambientes vulneráveis como as casas localizadas em margens de rios, encosta íngremes e com materiais de baixa qualidade que podem trazer sérios riscos para as populações que residem nesses ambientes e que contribuem para a instabilidade desses terrenos por meio da presença de água servida (esgoto), desmatamento e assoreamentos dos rios.

Foi utilizado como atividade de fixação dos conteúdos passados na palestra o Mapeamento de Risco, onde os alunos deveriam registrar os tipos de riscos que poderiam ocorrer ao redor da escola (através de imagens adquiridas no Google Earth) ou nos bairros adjacentes a ela. Por meio desta atividade os estudantes têm o poder de mapear qualquer situação que eles possam considerar perigosa ou que podem colocá-los em situação de risco dentro do seu espaço de vivência. Após a atividade de mapeamento os alunos são convidados a relatarem para os seus colegas de turma os riscos que eles consideraram ser importantes para colocar no mapa seja pelo seu grau de ocorrência na região onde estudam ou pelas características do local, pela presença de rios, encostas, bueiros entupidos entre outros.

\section{Resultados e Discussões}

As experiências com as palestras possibilitaram uma nova forma de abordar os assuntos voltados para as questões ambientais de forma mais didáticas em sala de aula. Logo, utilizar o cotidiano do aluno nos conteúdos escolares se torna uma estratégia central para desenvolver não só a percepção de riscos, mas também para desenvolver os processos de ensino-aprendizagem. Segundo Afonso (2013) é muito importante entender as dinâmicas naturais e como elas interagem com a sociedade para melhor compreender o espaço geográfico e as suas situações de risco. Portanto, os assuntos voltados para as dinâmicas da natureza precisam ser valorizados e abordados dentro dos conteúdos pertencentes a Geografia Física. Os alunos se mostraram bem interessados com a temática, visto que, segundo eles é algo que estão presentes em seu cotidiano e que são importantes de serem abordados, pois são tipos de eventos que podem causar perdas humanas, de materiais, econômicas, ambientais entre outros, causando grandes prejuízos para a população. Os estudantes já tinham as suas percepções e noções do que eram os riscos naturais e dos conceitos trabalhados na palestra. $\mathrm{O}$ ambiente em sala de aula se tornou bem dinâmico, pois os alunos interagiam o tempo todo, relatando as experiências vividas por eles ou pelo contato que tiveram com a temática por meio das mídias sociais. Foi utilizado os exemplos de riscos naturais que ocorreram próximos a eles como os deslizamentos que ocorreram na Região Serrana do Rio de Janeiro em 2011, no Morro do Bumba em Niterói em 2010 e a inundação excepcional que ocorreu em Alcântara, São Gonçalo em 2010.

Com o mapeamento de riscos os estudantes passam a identificar e a espacializar os tipos de acidentes que podem ocorrer em seu lugar de vivência, isto Ihes proporcionam um olhar diferentes sobre os espaços onde se deslocam, diminuindo a sua vulnerabilidade em relação a um possível risco. A partir daí, podem se tornam cidadãos que serão capazes de perceber os problemas que podem ser encontrados nas paisagens

ParaOnde!?, Porto Alegre, v.12 n.2, p.89-95, 2019.http://seer.ufrgs.br/paraonde Edição Especial - III Colóquio de Pesquisadores em Geografia Física Ensino de Geografia 
das cidades como: construções em áreas íngremes, a ocupação e o uso do solo desordenado, construções sobre aterros, o corte de taludes, lançamento de lixo e águas nas encostas, que são fatores que intensificam os movimentos de massa e deslizamentos, possibilitando também à compreensão do espaço geográfico, mostrando que a natureza não está externa ao homem e sim conectada. Percebeu-se a priori que os alunos concebiam de maneira equivocada o conceito de riscos, referindo-se a violência urbanas nas cidades e não aos riscos naturais, entretanto ao notar isso, desenvolvemos junto com eles os conceitos importantes para se entender as situações de riscos geomorfológicos como os que já foi dito acima os conceitos referentes a riscos, vulnerabilidade, instabilidade, ameaça entre outros.

As palestras realizadas pelo grupo de pesquisa foram realizadas em Escolas Estaduais no Município de São Gonçalo, o CIEP 439 Luís Gonzaga Júnior (2016-2018) e no Ciep Vital Brasil (2017), no intuito de divulgar as informações de prevenção e mitigação de riscos naturais e aproximar a Universidade da Escola Básica, na perspectiva na Educação Ambiental.

As palestras realizadas em escolas públicas do Município de São Gonçalo, tendo como base o projeto elaborado pela Defesa Civil da Cidade do Rio de Janeiro (DCRJ), faz parte do projeto do grupo de pesquisa "Ensino de Geografia Física e Formação de Professores" do DGEO/FFP/UERJ em parceria com a DCRJ. E que, portanto, tem possibilidade de continuação para que futuros bolsistas possam assumir esta linda tarefa de perpetuar os conhecimentos adquiridos na academia para o ensino básico a fim de que os conhecimentos da Geografia Física e as informações sobre prevenção de riscos naturais possam ser disseminados não só na escola, mas também para a sociedade e principalmente para aqueles que residem em áreas ambientalmente vulneráveis. Portanto, este projeto se torna muito importante para ser inserido tanto em oficinas voltadas para questões voltadas para o meio ambiente quanto nos próprios conteúdos escolares obrigatórios e isso contribuirá para o desenvolvimento de cidadãos mais conscientes e engajados nas questões sociais e ambientais.

\section{Considerações finais}

De fato, percebe-se a importância do aprendizado e dos conhecimentos sobre as dinâmicas da natureza como um instrumento eficaz na disseminação de informações sobre riscos naturais e como forma de prevenção e mitigação de riscos. É importante que os conteúdos referentes a Geografia Física estejam voltados para o cotidiano do aluno de modo que isto facilite a compreensão deles sobre os fatores físicos-ambientais que estão presentes ao nosso redor e funcionam de maneira integrada na natureza. É importante que os estudantes por meio do ensino significativo saibam o que fazer em períodos de chuvas fortes e prolongadas ou em caso de situações de perigo ou risco. A educação escolar precisa fazer sentido para os alunos de modo que esses conhecimentos possam mudar de forma positiva a forma como eles concebem o meio onde vivem e o mundo, tornando-se cidadãos conscientes e engajados em questões ambientais, sociais, econômicas e políticas para que a mudança possa se tornar uma realidade e não ficar apenas no papel.

ParaOnde!?, Porto Alegre, v.12 n.2, p.89-95, 2019.http://seer.ufrgs.br/paraonde Edição Especial - III Colóquio de Pesquisadores em Geografia Física Ensino de Geografia 


\section{REFERÊNCIAS}

AFONSO, A.E. Geografia Física aplicada ao ensino: educação ambiental e prevenção de riscos naturais na formação de professores. in:xv simpósio brasileiro de geografia física aplicada (sbgfa). Uso e Ocupação da Terra e as Mudanças das Paisagens.Vitória (ES) 08 a 12 de Julho de 2013. Departamento de Geografia2013. CCHN,UFES. P.153-161.

CEPEDE, UFSC, Centro Universitário de Estudos e Pesquisa Sobre Desastres. Brasil Cresce Seguro: Proposta de Redução de Risco de Desastres nas Escolas- v. 4 Guia conceitual em Redução de Risco de Desastre, Florianópolis, 2012. 